\title{
Case Report Multiseptate Gallbladder in an Asymptomatic Child
}

\author{
Dylan Wanaguru, ${ }^{1}$ Ashish Jiwane, ${ }^{1}$ Andrew S. Day, ${ }^{2,3}$ and Susan Adams ${ }^{1}$ \\ ${ }^{1}$ Department of Paediatric Surgery, Sydney Children's Hospital, University of New South Wales, High Street, Randwick, Sydney, \\ NSW 2031, Australia \\ ${ }^{2}$ Department of Gastroenterology, University of New South Wales, High Street, Randwick, NSW 2031, Australia \\ ${ }^{3}$ Sydney Children's Hospital and School of Women's and Children's Health, University of New South Wales, High Street, Randwick, \\ NSW 2031, Australia
}

Correspondence should be addressed to Dylan Wanaguru, d.wanaguru@yahoo.com.au

Received 3 July 2011; Accepted 21 July 2011

Academic Editors: F.-Y. Chang, K. Haruma, and A. J. Lembo

Copyright ( 2011 Dylan Wanaguru et al. This is an open access article distributed under the Creative Commons Attribution License, which permits unrestricted use, distribution, and reproduction in any medium, provided the original work is properly cited.

A one-year-old child being investigated for urinary tract infection was diagnosed with a multiseptate gallbladder. The patient remains asymptomatic, and investigations demonstrate no associated anomalies. Forty-three cases, including 13 cases in children were identified in the literature. Their presentation and management were reviewed.

\section{Introduction}

Multiseptate gallbladder (MSG) is a rare congenital anomaly with less than 50 cases described in the English literature. Of these, 13 are in paediatric patients [1-9]. We report a case of MSG in a one-year-old child. We review the data from the published literature to consider the most appropriate management of symptomatic and asymptomatic children, including whether or not cholecystectomy is indicated.

\section{Case Report}

A nine-month-old, previously well, female infant presented with an acute episode of vomiting and was diagnosed with an Escherichia coli urinary tract infection (UTI). Renal tract ultrasound was normal, but the gallbladder (GB) was incidentally noted to have "multiple thin smooth septa, giving a honeycomb appearance," consistent with MSG (Figure 1). No other biliary tract abnormality was noted. The UTI was treated, and the child subsequently remained asymptomatic.

Repeat ultrasound six months later showed the images were unaltered. Liver function tests were normal apart from a raised alkaline phosphatase $1632 \mathrm{U} / \mathrm{L}$ (age appropriate normal range 80-450). Magnetic resonance cholangiopancreaticography (MRCP) confirmed the diagnosis of MSG, and excluded intra- and extrahepatic biliary and pancreatic anomalies. Nuclear medicine HIDA (hepatobiliary iminodiacetic acid) scan revealed no evidence of obstruction to bile flow at any level of the biliary tree.

\section{Discussion}

Multiseptate gallbladder was first described in 1963 by Simon and Tandon [10]. It is characterised by multiple thin septations within the gallbladder lumen, giving a honeycomb-like appearance. Simon and Tandon [10] proposed that this was due to incomplete vacuolisation of the developing gallbladder bud. Bhagavan et al. [11] have suggested that MSG may be a result of the solid embryonic GB growing faster than its bed and investing peritoneum, causing aberrant bends and kinks. The same authors also postulate that a variation in the wrinkling, lobulation, and clefting of the gallbladder (seen in cat and guinea pig embryos) may result in multiseptation [11].

Including the current case, 44 cases are described in the English literature, with a male-to-female ratio of almost $1: 2$. Overall the mean age at diagnosis of these individuals was 28.6 years (range from 15 days to 70 years). Thirty of these cases were in adults [10-36]. Thirteen have been reported in children: eight being female (Table 1) [1-9]. Most children 
TABLE 1: Published reports of multiseptate gallbladder in children and adolescents (aged less than 16 years).

\begin{tabular}{|c|c|c|c|c|c|c|}
\hline Author (reference) & Year & Age & Sex & Biliary symptoms & Associated anomalies & Treatment \\
\hline Haslam et al. [1] & 1966 & 15 & $\mathrm{~F}$ & Yes & Nil & Cholecystectomy \\
\hline Pery et al. [2] & 1985 & 8 & $\mathrm{~F}$ & Yes & Choledochal cyst & $\begin{array}{l}\text { Cholecystectomy and } \\
\text { choledochoduodenostomy }\end{array}$ \\
\hline Fremond et al. [3] & 1989 & 13 & $\mathrm{~F}$ & Yes & Nil & Cholecystectomy \\
\hline Adear and Barki [4] & 1990 & 12 & $\mathrm{~F}$ & No & Nil & Nil \\
\hline Strauss et al. [5] & 1993 & 3 & M & No & Nil & Not detailed \\
\hline Strauss et al. [5] & 1993 & 9 & $\mathrm{~F}$ & Yes & Nil & Not detailed \\
\hline Strauss et al. [5] & 1993 & 16 & $\mathrm{M}$ & Yes & Nil & Not detailed \\
\hline Tan et al. [6] & 1993 & 14 & $\mathrm{~F}$ & Yes & Choledochal cyst & $\begin{array}{l}\text { Cholecystectomy and } \\
\text { hepatojejunostomy }\end{array}$ \\
\hline Kocakoc et al. [7] & 2003 & 9 & $\mathrm{M}$ & Yes & Nil & Cholecystectomy \\
\hline Erdogmus et al. [8] & 2004 & 10 & $\mathrm{~F}$ & Yes & Nil & Cholecystectomy \\
\hline Erdogmus et al. [8] & 2004 & 12 & $\mathrm{M}$ & Yes & Nil & Cholecystectomy \\
\hline Bahadir et al. [9] & 2006 & 15 days & $\mathrm{M}$ & Yes & $\begin{array}{l}\text { Ectopic pancreas associated } \\
\text { with choledochal cyst }\end{array}$ & $\begin{array}{l}\text { Total excision of cyst with } \\
\text { Roux-en-Y anastomosis }\end{array}$ \\
\hline Present Case & 2008 & 1 & $\mathrm{~F}$ & No & Nil & Monitor with ultrasound \\
\hline
\end{tabular}

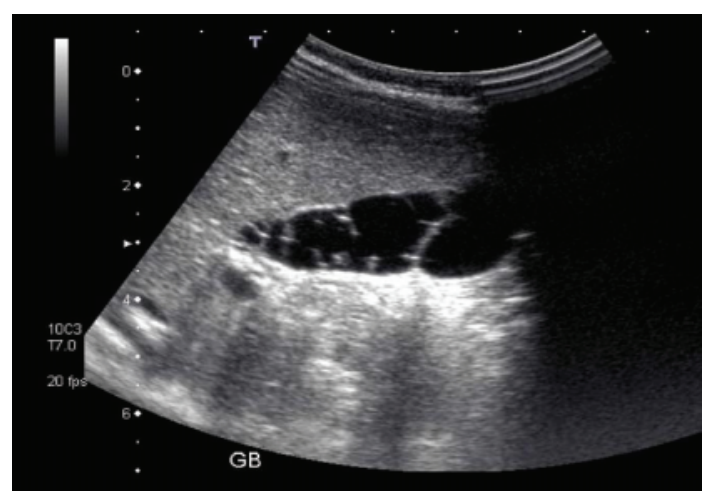

FIGURE 1: Ultrasound image demonstrating multiple fine septations within the gallbladder.

were diagnosed in mid-to-late childhood (mean age 9.4 years) although one was detected at 15 days of age.

Biliary symptoms such as right upper quadrant pain, nausea and vomiting are the most common complaints in this condition, with 31 of the 44 cases presenting in this manner. Only three of the 44 cases were associated with cholelithiasis $[8,12,13]$, and one was associated with acute acalculous cholecystitis [14], but none of these were in children. The presence of an associated biliary tract abnormality is an important consideration in the assessment of MSG. One case in a 46-year-old woman was associated with anomalous pancreaticobiliary ductal union [15]. The three reported cases found to have associated choledochal cysts were all in children (23\% of paediatric cases). These children presented with jaundice $[2,9]$ and a combination of fever, nausea, and abdominal discomfort [6]. Seven of the remaining 10 children presented with biliary symptoms $[1,3,5,7,8]$. The other three children (including the current

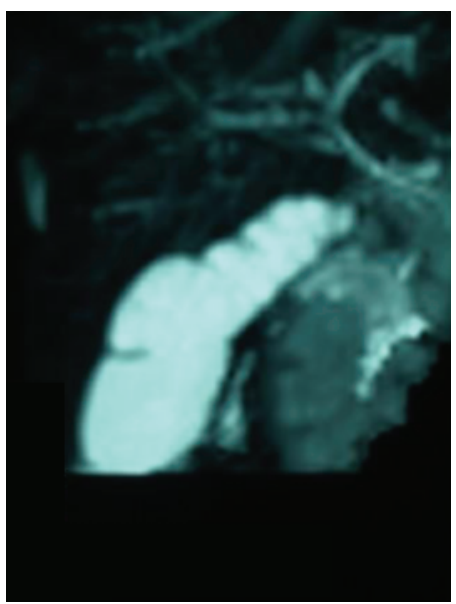

FIGURE 2: Magnetic Resonance cholangiopancreaticography (MRCP) image confirming ultrasound findings of multiple septae within the gallbladder.

case) were asymptomatic with no biliary tract anomaly $[4,5]$. The incidence of asymptomatic MSG in the community is unknown, so it is not possible to comment on the likelihood of symptoms developing in these children.

There is no reported association between uncomplicated MSG and malignancy; however, there is a known link between biliary tract anomalies and cholangiocarcinoma. The incidence of malignancy in choledochal cyst is reported between $10 \%$ and $30 \%$, and anomalous arrangement of the pancreaticobiliary duct is considered to be a high-risk factor for biliary tract malignancy $[16,17]$. Consequently, four of the reported cases of MSG (all adults) with such associated abnormalities have an increased long-term risk of malignancy. 
The majority of reported cases were diagnosed on ultrasound. Differential diagnosis includes desquamated gallbladder mucosa, polypoid cholesterolosis, hydatid cyst and acute hepatitis [18, 19]. Kocakoc et al. [7] first reported the use of MRCP to noninvasively define biliary and pancreatic pathology in MSG. MRCP is useful in confirming the diagnosis and delineating any associated biliary tree pathology and eliminates the potential complications associated with endoscopic cholangiopancreaticography (ERCP).

Saimura et al. [19] conducted biliary manometry and scintigraphy on a 30-year-old man with epigastric pain and MSG. Impairment of bile flow into and out of the gallbladder was demonstrated, supporting a biliary origin of the patient's pain. In the same study, Saimura and colleagues went on to reproduce typical biliary colic in the patient by injection of Cerulein to stimulate gallbladder contraction.

In symptomatic patients diagnosed with MSG, cholecystectomy provides relief of symptoms [21]. The three children with associated choledochal cyst were successfully treated with excision of the extrahepatic biliary tree combined with hepatojejunostomy or choledochoduodenostomy. In the 12 reported cases of asymptomatic and uncomplicated MSG, including the three paediatric cases, management has been nonoperative with regular followup.

\section{Conclusion}

MSG is a rare biliary anomaly that may be diagnosed in the first decades of life. Associated biliary tract anomalies should be excluded, particularly when the diagnosis is made in childhood. Cholelithiasis is rarely associated with MSG, and has never been reported in a child. Investigation with ultrasound, MRCP, and HIDA scan is recommended. In the absence of symptoms attributable to the MSG, or an associated biliary tract anomaly, nonoperative management in children and regular followup is reasonable. Symptomatic uncomplicated MSG is successfully treated with cholecystectomy.

\section{References}

[1] R. H. Haslam, B. W. Gayler, and P. A. Ebert, "Multiseptate gallbladder. A cause of recurrent abdominal pain in childhood," American Journal of Diseases of Children, vol. 112, no. 6, pp. 600-603, 1966.

[2] M. Pery, J. K. Kaftori, and H. Marvan, "Ultrasonographic appearance of multiseptate gallbladder: report of a case with coexisting choledochal cyst," Journal of Clinical Ultrasound, vol. 13 , no. 8, pp. 570-573, 1985.

[3] B. Fremond, C. Stasik, H. Jouan et al., "The multiseptate gallbladder. A rare malformation of the biliary tract," Chirurgie Pediatrique, vol. 30, no. 6, pp. 292-294, 1989.

[4] H. Adear and Y. Barki, "Multiseptate gallbladder in a child: incidental diagnosis on sonography," Pediatric Radiology, vol. 20, no. 3, p. 192, 1990.

[5] S. Strauss, R. Starinsky, and Z. Alon, "Partial multiseptate gallbladder: sonographic appearance," Journal of Ultrasound in Medicine, vol. 12, no. 4, pp. 201-203, 1993.

[6] C. E. L. Tan, E. R. Howard, M. Driver, and I. M. Murray-Lyon, "Non-communicating multiseptate gall bladder and choledochal cyst: a case report and review of publications," Gut, vol. 34, no. 6, pp. 853-856, 1993.
[7] E. Kocakoc, A. Kiris, A. Alkan, Z. Bozgeyik, Y. Sen, and H. Ozdemir, "Multiseptate gallbladder in a child with chronic abdominal pain: ultrasonography, magnetic resonance imaging and magnetic resonance cholangiography findings," European Journal of Radiology Extra, vol. 47, no. 1, pp. 22-25, 2003.

[8] B. Erdogmus, B. Yazici, B. A. Ozdere, and Y. Akcan, "Clinical and ultrasonographical findings in patients with multiseptate gallbladder," Tohoku Journal of Experimental Medicine, vol. 204, no. 3, pp. 215-219, 2004.

[9] B. Bahadir, S. O. Ozdamar, B. D. Gun, S. Bektas, K. V. Numanoglu, and G. M. Kuzey, "Ectopic pancreas associated with choledochal cyst and multiseptate gallbladder," Pediatric and Developmental Pathology, vol. 9, no. 4, pp. 312-315, 2006.

[10] M. Simon and B. N. Tandon, "Multiseptate gallbladder. A case report," Radiology, vol. 80, pp. 84-86, 1963.

[11] B. S. Bhagavan, P. B. Amin, A. S. Land, and T. Weinberg, "Multiseptate gallbladder. Embryogenetic hypotheses," Archives of pathology, vol. 89, no. 4, pp. 382-385, 1970.

[12] E. J. Croce, “The multiseptate gallbladder," Archives of Surgery, vol. 107, no. 1, pp. 104-105, 1973.

[13] B. Erdogmus, B. Yazici, A. A. Safak, and B. A. Ozdere, "Multiseptate gallbladder with acute acalculous cholecystitis," Journal of Clinical Ultrasound, vol. 32, no. 8, pp. 423-424, 2004.

[14] T. Yamamoto, J. Matsumoto, S. Hashiguchi, A. Yamaguchi, K. Sakoda, and C. Taki, "Multiseptate gallbladder with anomalous pancreaticobiliary ductal union: a case report," World Journal of Gastroenterology, vol. 11, no. 38, pp. 6066-6068, 2005.

[15] M. S. Metcalfe, S. A. Wemyss-Holden, and G. J. Maddern, "Management dilemmas with choledochal cysts," Archives of Surgery, vol. 138, no. 3, pp. 333-339, 2003.

[16] S. Ono, K. Sakai, O. Kimura, and N. Iwai, "Development of bile duct cancer in a 26-year-old man after resection of infantile choledochal cyst," Journal of Pediatric Surgery, vol. 43, no. 6, pp. E17-E19, 2008.

[17] T. Nakazawa, H. Ohara, H. Sano et al., "Multiseptate gallbladder: diagnostic value of MR cholangiography and ultrasonography," Abdominal Imaging, vol. 29, no. 6, pp. 691-693, 2004.

[18] A. Türkvatan, A. Erden, M. Çelik, and T. Ölçer, "Ectopic hypoplastic and multiseptate gallbladder with coexisting choledochal cyst: evaluation with sonography and magnetic resonance cholangiopancreaticography," Journal of Clinical Ultrasound, vol. 34, no. 2, pp. 88-91, 2006.

[19] M. Saimura, H. Ichimiya, G. Naritomi et al., "Multiseptate gallbladder: biliary manometry and scintigraphy," Journal of Gastroenterology, vol. 31, no. 1, pp. 133-136, 1996.

[20] V. Kapoor, M. P. Federle, M. S. Peterson, and D. A. Coll, "Long-term sonographic follow-up of stable imaging findings of multiseptate gallbladder," Journal of Ultrasound in Medicine, vol. 21, no. 6, pp. 677-680, 2002.

[21] R. L. Bigg, "Multiseptate gallbladder," Archives of Surgery, vol. 88, no. 3, pp. 501-502, 1964.

[22] R. B. Shaw, C. A. Donato, and D. D. Douglas, "Multiseptate gallbladder diagnosed during pregnancy," American Surgeon, vol. 41, no. 12, pp. 818-822, 1975.

[23] P. K. Jena, R. A. Hardie, and M. Hobsley, "Multiseptate hypoplastic gallbladder," British Journal of Surgery, vol. 64, no. 3, pp. 192-193, 1977.

[24] K. Okuda, M. Nakajima, M. Nakayama, and F. Nomura, "Multiseptate gallbladder. Report of a case with a review of literature," Acta Hepato-Gastroenterologica, vol. 26, no. 1, pp. 7075, 1979. 
[25] B. D. Toombs, E. Foucar, B. J. Rowlands, and R. Strax, "Multiseptate gallbladder," Southern Medical Journal, vol. 75, no. 5, pp. 610-612, 1982.

[26] I. O. Oliva, M. R. Moran, F. Sanchez, and A. G. Alonso, "Multiseptate gallbladder," International Surgery, vol. 70, no. 1, pp. 83-84, 1985.

[27] A. S. Lev-Toaff, A. C. Friedman, and S. N. Rindsberg, "Multiseptate gallbladder: incidental diagnosis on sonography," American Journal of Roentgenology, vol. 148, no. 6, pp. 1119 1120, 1987.

[28] I. Isomoto, N. Matsunaga, M. Ochi et al., "Multiseptate gallbladder: computed tomographic appearance," Radiation $\mathrm{Me}$ dicine, vol. 8, no. 2, pp. 55-57, 1990.

[29] P. Vasinrapee, K. Linden, and R. E. Cook, "Multiseptate gallbladder demonstrated on Tc-99m hepatobiliary imaging," Clinical Nuclear Medicine, vol. 15, no. 4, p. 272, 1990.

[30] K. B. Hahm, D. S. Yim, J. K. Kang, and I. S. Park, "Cholangiographic appearance of multiseptate gallbladder: case report and a review of the literature," Journal of Gastroenterology, vol. 29, no. 5, pp. 665-668, 1994.

[31] G. Naritomi, H. Kimura, H. Konomi et al., "Multiseptate gallbladder as a cause of biliary pain," American Journal of Gastroenterology, vol. 89, no. 10, pp. 1891-1892, 1994.

[32] M. L. Paciorek, D. Lackner, C. Daly, and G. Sekas, "A unique presentation of multiseptate gallbladder," Digestive Diseases and Sciences, vol. 42, no. 12, pp. 2519-2523, 1997.

[33] D. Saddik, "Multiseptate gall-bladder: incidental diagnosis on ultrasound," Australasian Radiology, vol. 42, no. 4, pp. 374376, 1998.

[34] W. Miwa, K. Toyama, Y. Kitamura et al., "Multiseptate gallbladder with cholelithiasis diagnosed incidentally in an elderly patient," Internal Medicine, vol. 39, no. 12, pp. 1054-1059, 2000.

[35] E. Kocakoc, A. Kiris, and Z. Bozgeyik, "Multiseptate gallbladder: MR and MR cholangiographic findings," Abdominal Imaging, vol. 30, no. 4, p. 501, 2005.

[36] A. Yamasaki, K. Chijiiwa, S. I. Jimi et al., "Multiseptate gallbladder: report of a case," Hepato-Gastroenterology, vol. 55, no. 84, pp. 859-860, 2008. 


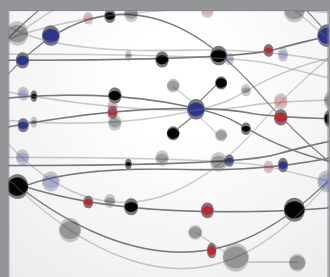

The Scientific World Journal
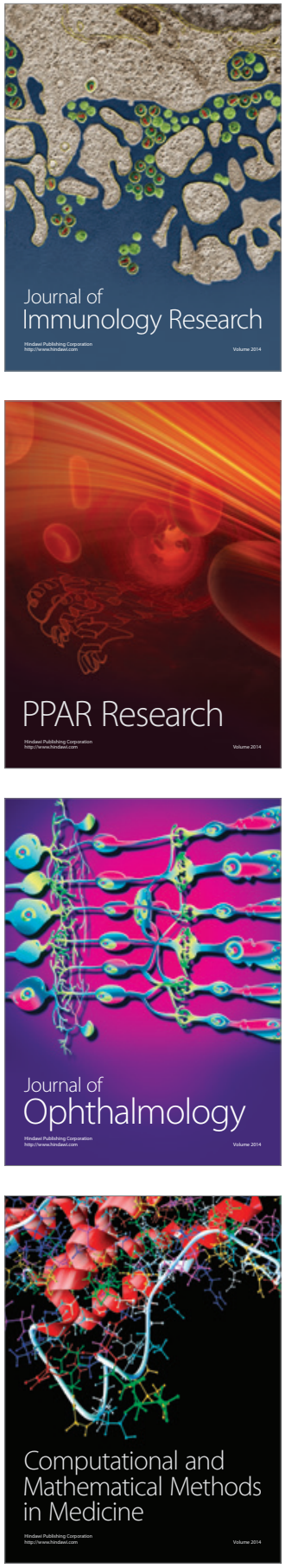

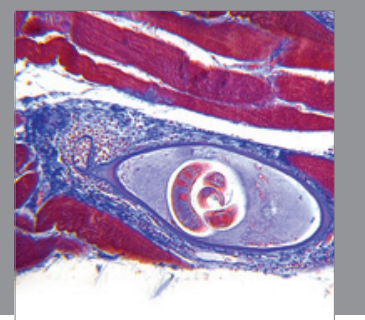

Gastroenterology

Research and Practice
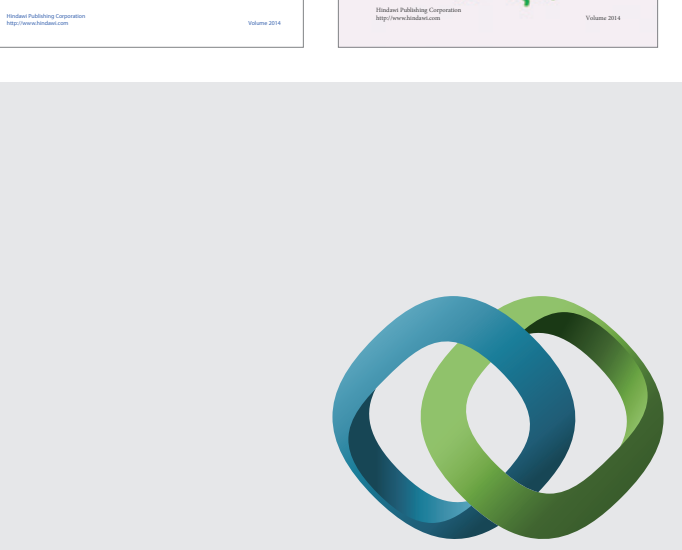

\section{Hindawi}

Submit your manuscripts at

http://www.hindawi.com
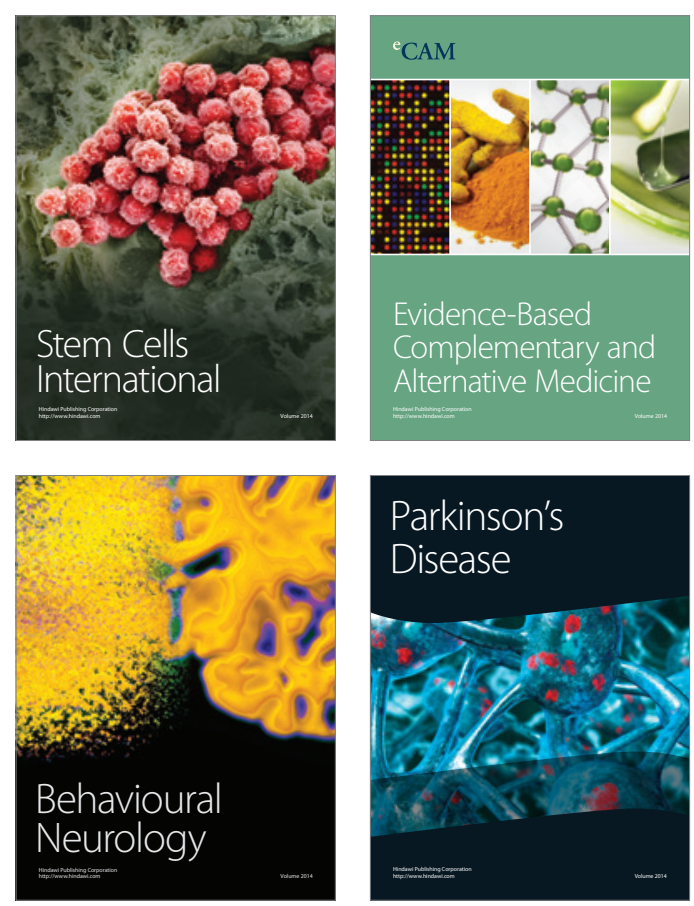

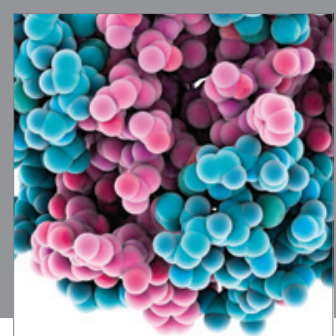

Journal of
Diabetes Research

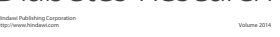

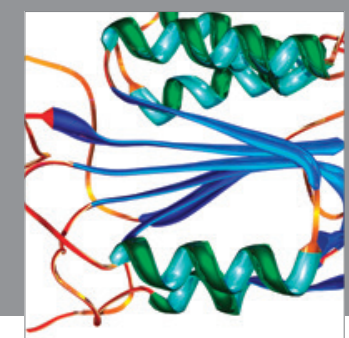

Disease Markers
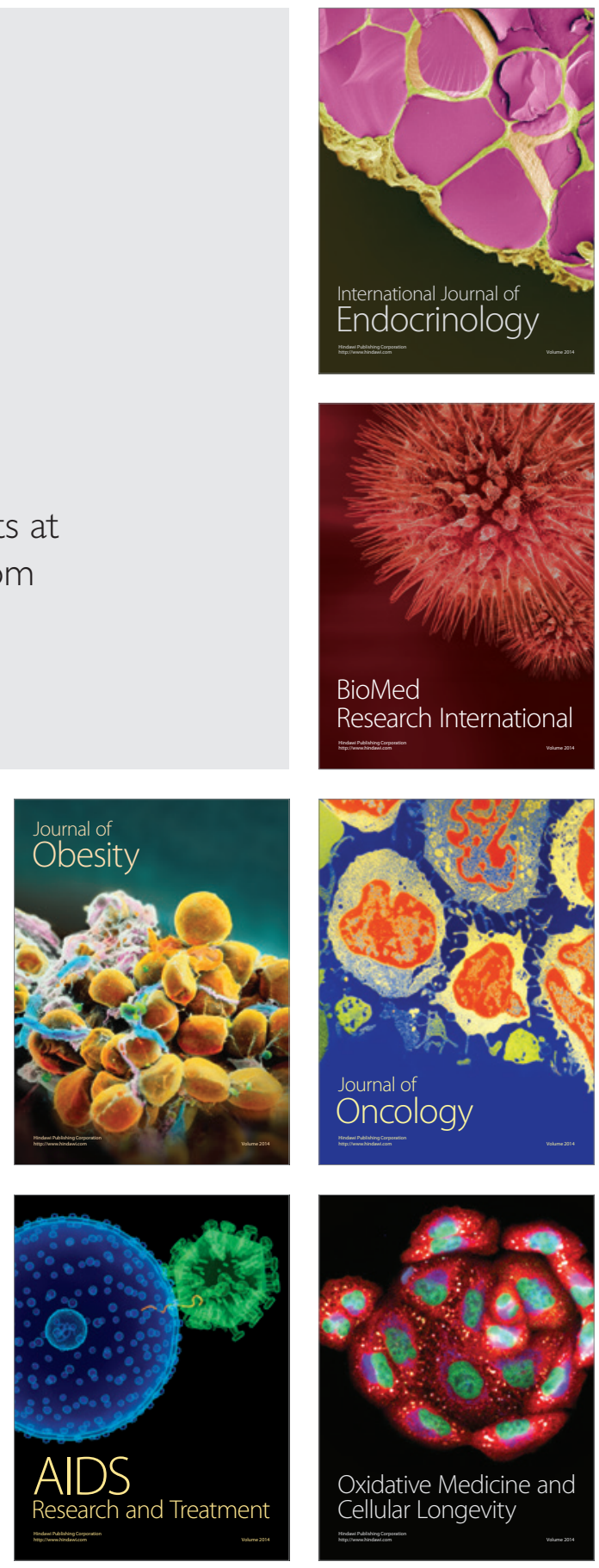